\title{
Ultrasonic Water Measurement in Irrigation Pipelines With Disturbed Flow
}

\author{
A. L. Johnson, B. L. Benham, D. E. Eisenhauer, R. H. Hotchkiss
}

\begin{abstract}
Ultrasonic flow meter accuracy was investigated over a range of flow conditions ( 3 pipe materials, 2 pipe sizes, 4 Reynolds numbers, 7 flow-disturbing devices) commonly found in irrigation systems. Flow rate measurements were taken at five locations downstream from a flow disturbance. The measurement accuracy was within $\pm 5 \%$ of actual flow at a minimum of 10 pipe diameters downstream from the flow disturbances. Errors as high as $36.5 \%$ occurred when measurements were taken close to some flow disturbances. A multiplier was developed to correct for directional bias for devices that fell into the Group 1 category (single elbow, two elbows, check valve, and 50\% open butterfly valve with vertical and horizontal orientation). Applying the multiplier at 4.5 pipe diameters and higher resulted in accuracies within $\pm 4 \%$ of actual flow. The regression analysis performed on Group 1 devices showed that the USFM performance was not significantly different for the three pipe materials, two pipe diameters, and four flow rates.
\end{abstract}

Keywords. Ultrasonic measurement system, Water measurement, Irrigation pipeline metering.

$\mathrm{M}$ easuring water is one of the keys to better water management in irrigation. Many devices (such as the venturi, orifice, and propeller flow meters) are used to measure water flow in pipelines, as described by Replogle and Birth (1991). A relatively new alternative is the ultrasonic flow meter (USFM), a non-invasive device that can be used to obtain both flow rate and total volume. Clamp-on transducers eliminate in-line installation, allowing one meter to measure flow easily at many locations. Exterior installation eliminates pressure losses and prevents leaking that in-line installations may cause (Peek Industries, 1996; Riezenman, 1989). Typical accuracy of an ultrasonic flow meter is reported as $\pm 1 \%$ to $\pm 5 \%$ of full scale when installed according to manufacturer guidelines (Omega Engineering, 1992). Replogle et al. (1990) documented modern clamp-on transit-time flow meter accuracy of at least $\pm 2 \%$ of the meter reading.

The USFM is noninvasive, portable, and easy to use, and it can be installed at any point along the pipeline. The ease of use and installation flexibility make the USFM an attractive alternative to traditional in-line meters. However, these same characteristics make it easy to misuse the meter

Article was submitted for review in October 2000; approved for publication by the Soil \& Water Division of ASAE in May 2001.

Journal Series No. 13143 of the University of Nebraska Agricultural Research Division.

The authors are Amy L. Johnson, Senior Engineer, RTW Professional Engineers and Consultants, Inc., Fort Collins, Colorado; Brian L. Benham, ASAE Member Engineer, Assistant Professor, Biological Systems Engineering, Virginia Tech, Blackburg, Virginia; Dean E. Eisenhauer, ASAE Member Engineer, Professor, Biological Systems Engineering, University of Nebraska-Lincoln, Lincoln, Nebraska; and Rollin H. Hotchkiss, Associate Professor, Civil and Environmental Engineering, Washington State University, Pullman, Washington. Corresponding author: Brian L. Benham, Biological Systems Engineering, 205 Seitz Hall, Virginia Tech, Blackburg, VA 24061; phone: 540-231-5705; fax: 540-231-3199; e-mail: benham@vt.edu. and thus collect inaccurate data. The purpose of this study was to evaluate transit-time ultrasonic meter performance across a range of conditions and to develop a methodology to correct ultrasonic flow meter data that were collected under disturbed-flow conditions.

The transmission or transit-time ultrasonic flow meter operates on the principle of phase shift. Two transducers act alternately as transmitter and receiver as ultrasonic pulses are sent across the pipe at an angle incident to the principle direction of flow. One pulse travels downstream while the other moves upstream. The fluid motion causes a phase shift in both waves. Sound waves in the fluid move at a velocity equal to the sum of the speed of sound in the fluid and the velocity of the fluid (Cocking, 1994).

With the transit-time flow meter, fluid velocity in the metering section is determined by comparing the speed of sound pulses moving downstream with those moving upstream (ASME, 1985). Only under plug-flow conditions would one expect the velocity to be uniform across the pipe diameter. Normally, the velocity profile across the pipe is nonlinear, and velocities near the pipe wall are slower than those near the center. Volumetric flow rates in pipelines are calculated using the continuity equation:

$$
Q=V_{a} A_{p}
$$

where

$Q=$ volumetric flow rate $\left(\mathrm{m}^{3} \cdot \mathrm{s}^{-1}\right)$

$V_{a}=$ area-averaged velocity $\left(\mathrm{m} \cdot \mathrm{s}^{-1}\right)$

$A_{p}=$ cross-sectional area of measurement section $\left(\mathrm{m}^{2}\right)$.

$V_{a}$ is calculated using:

$$
V_{a}=\frac{1}{A_{p}} \int_{0}^{A_{p}} V d A
$$

where

$V=$ velocity at any point in the pipe $\left(\mathrm{m} \cdot \mathrm{s}^{-1}\right)$

$d A=$ differential area section $\left(\mathrm{m}^{2}\right)$. 
The USFM measures the average fluid velocity along the signal path using:

$$
V_{l}=\frac{1}{L} \int_{0}^{L} V d l
$$

where

$V_{l}=$ average fluid velocity along the signal path $\left(\mathrm{m} \cdot \mathrm{s}^{-1}\right)$

$L=$ length of signal path (m)

$d l=$ differential path length $(\mathrm{m})$.

A correction factor, $S$, is used within the USFM to convert the signal path velocity, $V_{l}$, to an area-averaged velocity, $V_{a}$ (ASME, 1985):

$$
V_{a}=S V_{l}
$$

where $S$ is the velocity profile correction factor (dimensionless). For fully developed profiles, $S$ ranges from 0.75 for laminar flow to 1.0 for plug flow.

The USFM correction factor assumes that the velocity profile in the measurement section is fully developed and symmetrical about the centerline of the pipe. When using the USFM, empirically developed correction factors are applied through internal software. The velocity corrections are transparent to the end user of the meter (Cocking, 1997).

The installation location of any flow measurement device affects accuracy. To ensure accurate flow rate measurement, the pipe upstream of the flow meter should include an adequate distance of straight pipe, free of flow-disturbing devices (U.S. DOI, 1997). Several recommendations for lengths of straight pipe preceding the meter can be found in the literature (Luckey et al., 1980; Omega Engineering, 1992; Upp, 1993; ISO, 1991). These recommendations vary greatly, but the goal of each recommendation is to provide a sufficient distance upstream of the metering section such that the velocity profile is fully developed at the metering section. The necessary length of straight pipe is based on pipe diameter and is commonly referred to as the number of required straight pipe diameters $\left(D_{p}\right)$. Recommendations range from 1.5 to $50 \mathrm{D}_{\mathrm{p}}$ between an upstream flow disturbance and the meter location.

The most common problem found in irrigation meter installations is an insufficient length of straight, unobstructed pipe upstream from the meter (Noffke, 1988). Because the ultrasonic flow meter is designed to operate in situations where fully developed velocity profiles exist, the accuracy of the USFM may suffer when it is used in less than ideal piping conditions, such as those often found in irrigation systems.

Hanson and Schwankl (1998) investigated flow rate measurement errors under what they called "nonoptimal" conditions caused by an elbow, a check valve, and a partially open butterfly valve. They evaluated eight different flow meters at distances of 2, 5, 10, and $15 \mathrm{D}_{\mathrm{p}}$ downstream from a flow disturbance. Measurements were made in a $20.3 \mathrm{~cm}$ Schedule 40 polyvinyl chloride (PVC) pipe. Across the range of tested flow rates, the error associated with the ultrasonic Doppler meter ranged from $+98.4 \%$ when installed $2 \mathrm{D}_{\mathrm{p}}$ downstream from a combined flow disturbance of a partially closed butterfly valve and a $90^{\circ}$ elbow, to $-22.6 \%$ when installed $15 \mathrm{D}_{\mathrm{p}}$ downstream from a partially closed butterfly valve.

\section{OвJECTIVES}

The objectives of this research were:

- To investigate the effects of flow-disturbing devices and their interaction with pipe size, pipe material, and Reynolds number on transit-time ultrasonic flow meter accuracy.

- To develop application guidelines for the transit-time ultrasonic flow meter when used in irrigation piping configurations that cause flow disturbances.

\section{MeTHODS}

Experiments were conducted in the Biological Systems Engineering hydraulics laboratory located in L. W. Chase Hall, University of Nebraska-Lincoln. For this study, non-ideal piping configurations were created using three flow-disturbing devices: a $90^{\circ}$ elbow, a check valve, and a butterfly valve. All devices were connected with flanged fittings. Standard radius steel elbows were used for all elbow tests. The check valve was a spring-loaded swing type (model 1778-62, Pierce Corporation). A wafer-style, lever-operated butterfly valve manufactured by Grinnell was used. These devices were arranged to produce seven different flow-disturbing configurations (table 1). There was a minimum of $20 \mathrm{D}_{\mathrm{p}}$ of straight, unobstructed pipe upstream from each flow-disturbing configuration. Three pipe materials were used: PVC, Class 20 steel, and aluminum (table 2). Table 3 shows the tested combinations of the pipe material, diameter, and flow disturbance. Ultrasonic flow meter (USFM) performance was evaluated at four different flow rates for each test combination shown in table 3. To ensure that the characteristics of the flow were consistent across pipe diameters and materials, test flow rates were defined using the Reynolds number (Re). Table 4 shows the target $\mathrm{Re}$ and the corresponding flow rate for each pipe diameter and material.

A Polysonics Model ISTT-P portable transit-time USFM was used for this experiment. The manufacturer's stated range and accuracy for this meter is: "flow range equals \pm 0 to $15 \mathrm{~m} \cdot \mathrm{s}^{-1}$; accuracy equals \pm 0.5 percent of velocity" (Peek Industries, 1996). Flow rates were measured at distances of $2,4.5,10,22$, and $50 \mathrm{D}_{\mathrm{p}}$ downstream from each flow

Table 1. Flow-disturbing devices and corresponding abbreviations.

\begin{tabular}{cl}
\hline Abbreviation & Flow-Disturbing Device \\
\hline SEL & Single elbow, elbow radius in horizontal plane \\
2EL & 2 elbows, different planes \\
CHK & Check valve, horizontal axis \\
BH5 & Butterfly valve, horizontal axis, $50 \%$ open \\
BH1 & Butterfly valve, horizontal axis, 100\% open \\
BV5 & Butterfly valve, vertical axis, $50 \%$ open \\
BV1 & Butterfly valve, vertical axis, $100 \%$ open \\
\hline
\end{tabular}

Table 2. Dimensions of pipe used in experiments.

\begin{tabular}{lcccc}
\hline & $\begin{array}{c}\text { Nominal } \\
\text { Size, } \\
\text { Material }\end{array}$ & $\begin{array}{c}\text { Inside } \\
\text { Diameter, } \\
\text { cm (in.) }\end{array}$ & $\begin{array}{c}\text { Wall } \\
\text { Thickness, } \\
\text { cm (in.) }\end{array}$ & $\begin{array}{c}\text { Flow } \\
\text { Area, } \\
\mathrm{cm}^{2}\end{array}$ \\
\hline Sch 40 PVC & $15.2(6)$ & $15.42(6.07)$ & $0.74(0.290)$ & 186.75 \\
Sch 40 PVC & $20.3(8)$ & $20.14(7.93)$ & $0.91(0.360)$ & 318.57 \\
Cl 20 Steel & $15.2(6)$ & $15.87(6.25)$ & $0.48(0.188)$ & 197.81 \\
Aluminum & $15.2(6)$ & $14.98(5.90)$ & $0.13(0.051)$ & 176.24 \\
\hline
\end{tabular}


Table 3. Matrix of flow-disturbing devices/configurations and pipe sizes and materials tested.

\begin{tabular}{lcccccccc}
\hline & \multicolumn{7}{c}{ Device and/or Configuration Tested } \\
\cline { 2 - 8 } Material & $\begin{array}{c}\text { Dia. } \\
(\mathrm{cm})\end{array}$ & SEL & 2EL & CHK & BH5 & BH1 & BV5 & BV1 \\
\hline PVC & 15.2 & $\mathrm{x}$ & $\mathrm{x}$ & $\mathrm{x}$ & $\mathrm{x}$ & $\mathrm{x}$ & $\mathrm{x}$ & $\mathrm{x}$ \\
PVC & 20.3 & $\mathrm{x}$ & - & - & - & - & - & - \\
Steel & 15.2 & $\mathrm{x}$ & $\mathrm{x}$ & $\mathrm{x}$ & $\mathrm{x}$ & $\mathrm{x}$ & $\mathrm{x}$ & $\mathrm{x}$ \\
Aluminum & 15.2 & $\mathrm{x}$ & - & - & - & - & - & - \\
\hline
\end{tabular}

disturbance. There was a minimum of $10 \mathrm{D}_{\mathrm{p}}$ of straight unobstructed pipe downstream from each measurement location. Flow meter transducers were mounted $90^{\circ}$ from the vertical axis on the left side of the pipe when facing upstream (fig. 1). In this configuration, flow rate measurements were made in the horizontal plane. Each test of a given flow-disturbing configuration consisted of mounting the flow meter transducers twice per measurement location. During each mounting, flow rate readings were recorded every $10 \mathrm{~s}$ over a $1-$ min period. The difference between the maximum and minimum ultrasonic readings during the $1-\min$ period varied from $0.53 \%$ to $4.86 \%$ of actual flow across all tests and Re. Flow rate readings were rounded to the third significant figure.

Ultrasonic flow meter measurements were compared to flow rate measurements made using the laboratory's two venturi meters (BIF Universal Flow Tubes): the 15.2-cm diameter venturi for flow rates less than $45 \mathrm{~L} \cdot \mathrm{s}^{-1}$, and the 20.3-cm diameter venturi for larger flow rates. A mercury manometer was used to measure differential head. The venturi served as the reference flow measurement device. Overall accuracy of the venturi is $\pm 1 \%$, as verified by volumetric tank calibrations.

To characterize the degree of velocity profile disruption caused by each flow-disturbing device, water velocity profiles were measured horizontally across the pipe with a Collins gage pitot tube. The Collins gage is a reversed cylindrical pitot device (ASME, 1971). Measurements were made using a standard 10-point test (Schroeder, 1985) with an additional point added in the center of the pipe. Measurement locations, a function of the pipe inside diameter (ID), were normalized by dividing by the pipe ID. Looking upstream, flow rate measurements were collected from left to right. Water velocities were normalized by dividing the point velocity by the average velocity, determined by dividing the reference flow rate by the cross-sectional area. For this study, velocity profiles were considered fully developed at $50 \mathrm{D}_{\mathrm{p}}$ based upon comparisons to theoretical profiles. The area weighted root mean square error (RMSE) was used to compare the measured velocity profiles to a theoretical fully developed profile, i.e.:

$$
R M S E=\sqrt{\frac{\sum_{i=1}^{n}\left(v_{i}-v_{t i}\right)^{2} \cdot A_{i}}{A}}
$$

where

$v_{i}=$ normalized velocity at point $i$ from Collins gage pitot tube measurement

$v_{t i}=$ calculated theoretical normalized velocity at point $i$

$A_{i}=$ the incremental cross-sectional area represented by point $i\left(\mathrm{~m}^{2}\right)$

$A=$ total cross-sectional area of pipe $\left(\mathrm{m}^{2}\right)$.

Calculated theoretical normalized velocities were found using the power law for smooth pipes (Daily and Harleman, 1966):

$$
\frac{v_{t}}{v_{\max }}=\left(\frac{y}{r}\right)^{\frac{1}{n}}
$$

where

$v_{t} \quad=$ normalized velocity at some distance $y$

$v_{\max }=$ normalized velocity at the centerline of the pipe

$y=$ distance from the pipe wall $(\mathrm{m})$

$r \quad=$ inside pipe radius $(\mathrm{m})$

$n \quad=$ exponent (dimensionless).

The shape of a fully developed profile is defined by the exponent $n$. For each flow-disturbing device, equation 6 was fit to the measured $50 \mathrm{D}_{\mathrm{p}}$ velocity profile using nonlinear regression. The resulting exponent values are presented in table 5. Miller (1989) presented a relationship where $n$ is a function of Re for smooth pipe. As shown in table 5, the $50 \mathrm{D}_{\mathrm{p}}$ regressed exponents compare well with theoretical values from Miller (1989). The largest difference between the theoretical and calculated exponents was $4.8 \%$. Based on the agreement between the exponent values, the $50 \mathrm{D}_{\mathrm{p}}$ velocity profile regression results were used in equation 6 to compute the $v_{t i}$ values needed for the RMSE calculation.

To evaluate USFM performance across the tested range of pipe materials, pipe diameters, flow rates, and measurement locations, a dimensionless flow ratio term (FR) was defined as:

$$
F R_{i j k}=\frac{Q_{u_{i j k}}}{Q_{v_{j k}}}
$$

where

$Q_{u i j k}=$ individual ultrasonic flow meter measurement $\left(\mathrm{L} \cdot \mathrm{s}^{-1}\right)$

$Q_{v j k}=$ venturi measurement for each Re, pipe material,

\begin{tabular}{|c|c|c|c|c|c|}
\hline \multirow{3}{*}{$\begin{array}{c}\text { Pipe } \\
\text { Diameter } \\
(\mathrm{cm})\end{array}$} & \multirow[b]{3}{*}{ Material } & \multicolumn{4}{|c|}{ Reynolds number (Re) } \\
\hline & & $\begin{array}{c}1.25 \times 10^{5} \\
\left(1.25 \times 10^{5}, 0.87\right)^{[\mathrm{a}]}\end{array}$ & $\begin{array}{c}2.51 \times 10^{5} \\
\left(2.49 \times 10^{5}, 0.61\right)^{[\mathrm{a}]}\end{array}$ & $\begin{array}{c}3.76 \times 10^{5} \\
\left(3.72 \times 10^{5}, 0.48\right)^{[\mathrm{a}]}\end{array}$ & $\begin{array}{c}5.02 \times 10^{5} \\
\left(5.00 \times 10^{5}, 0.50\right)^{[\mathrm{a}]}\end{array}$ \\
\hline & & \multicolumn{4}{|c|}{ Flow Rate, $\mathrm{L} \cdot \mathrm{s}^{-1}(\mathrm{gpm})$} \\
\hline 15.2 & $\mathrm{PVC}$ & $13.9(220)$ & $27.8(440)$ & $41.6(660)$ & $55.5(880)$ \\
\hline 20.3 & PVC & $18.1(287)$ & $36.3(575)$ & $54.4(862)$ & $72.6(1150)$ \\
\hline 15.2 & Steel & $14.3(226)$ & $28.6(453)$ & $42.8(679)$ & $57.2(906)$ \\
\hline 15.2 & Aluminum & $13.4(213)$ & 26.9 (427) & $40.5(642)$ & $53.9(854)$ \\
\hline
\end{tabular}
and pipe diameter combination $\left(\mathrm{L} \cdot \mathrm{s}^{-1}\right)$

Table 4. Flow rates necessary to obtain desired Reynolds numbers (Re).

[a] Mean Re averaged across all device, pipe material, and diameter combinations. Second number equals coefficient of variation $\left(\mathrm{C}_{\mathrm{v}}\right)$ expressed in percent. 


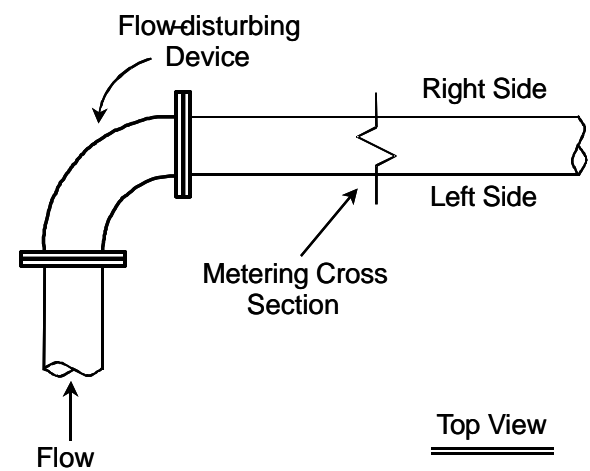

Figure 1. Plumbing and metering configuration (single elbow flow-disturbing device shown for illustration).

Table 5. Velocity profile regression parameters for $15.2 \mathrm{~cm}$ PVC.

\begin{tabular}{lcccc}
\hline & \multicolumn{4}{c}{ Desired Re } \\
\cline { 2 - 5 } & $1.25 \times 10^{5}$ & $2.51 \times 10^{5}$ & $3.76 \times 10^{5}$ & $5.02 \times 10^{5}$ \\
\hline$V_{\max }$ & 1.25 & 1.24 & 1.22 & 1.21 \\
$n_{\text {regressed }}$ [a] & 8.07 & 8.86 & 9.11 & 9.91 \\
$n_{\text {theoretical }}$ & 8.46 & 8.96 & 9.25 & 9.46 \\
$\quad \begin{array}{l}\text { Percent difference be- } \\
\text { tween regression and } \\
\quad \text { theoretical }\end{array}$ & 4.6 & 1.1 & 1.5 & 4.8 \\
\hline [a] & & & & \\
\hline
\end{tabular}

[a] Miller (1989).

$i=$ index for each observation, 1 to $12(\operatorname{six} 10-\mathrm{s}$ measurements $\times 2$ transducer mountings)

$j \quad=$ index for the four Re (test flow rates)

$k=$ index for each pipe material and pipe diameter combination.

FR data for the seven flow disturbances (devices) appeared to fall into two distinct categories. The first category, where the FR was less than 1 near the device but approached an asymptote of approximately 1 as the distance downstream from the device increased, is defined here as Group 1 and includes five flow-disturbing devices: SEL, 2EL, CHK, BV5, and BH5 (fig. 2). The second category, defined as Group 2, includes two flow-disturbing devices: BV1 and BH1 (fig. 3). The trends found for the devices in Group 2 were different and appeared less predictable than those for Group 1.

To confirm the hypothesis that, for a given flow disturbance, flow ratios were independent of $\mathrm{Re}$, pipe

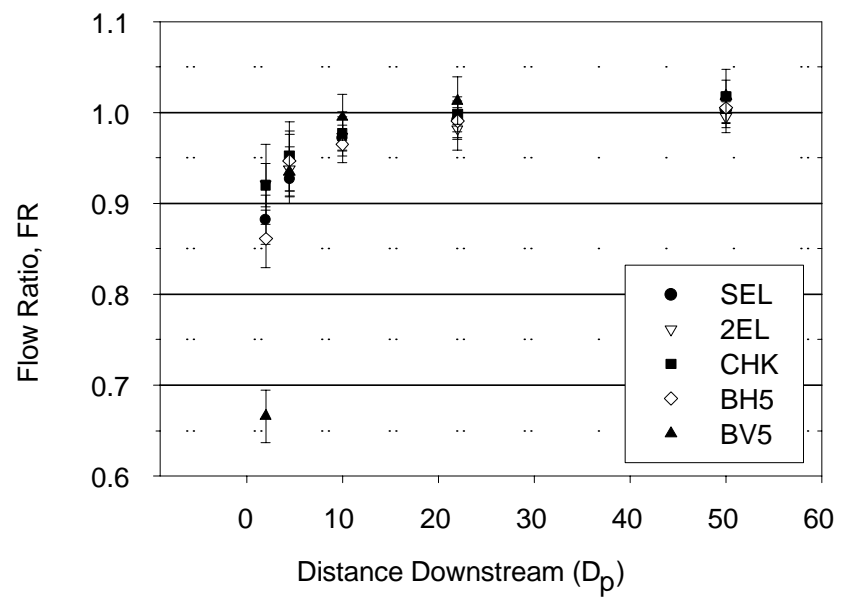

Figure 2. Group 1 flow ratio vs. $D_{p}$. Error bars are \pm 1 standard deviation.

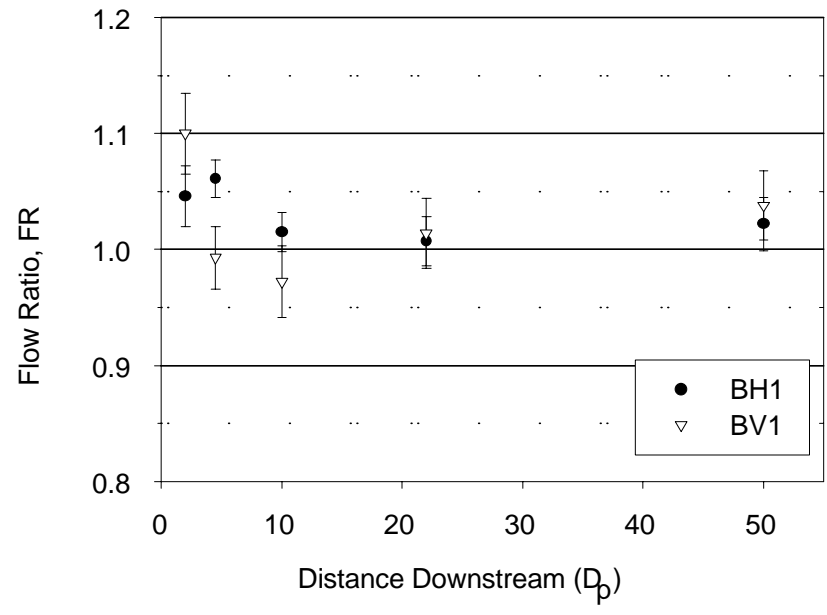

Figure 3. Group 2 flow ratio vs. $D_{p}$. Error bars are \pm 1 standard deviation.

material, and pipe diameter, equation 8 was fit for each of the five Group 1 devices for each pipe material, pipe diameter, and Re combination:

$$
F R=1-a \cdot e^{b \cdot D_{p}}
$$

where $a$ and $b$ are empirical parameters.

An ANOVA (SAS, 1987) analysis was performed on the resulting regression equations. No statistically significant differences $(\alpha=0.01)$ were found between the regressed fits within a given flow disturbance. Therefore, for data collected downstream from all of the five Group 1 devices, FR data were averaged within a given device. Based upon the analysis of the Group 1 devices, FR data for BV1 and BH1 were also pooled. An ANOVA analysis for BH1 and BV1 was not possible because the limited number of measurement locations did not provide adequate degrees of freedom to fit their response.

Assessment of the USFM accuracy followed the methodology outlined by Miller (1989) for bias and precision. The analysis of accuracy that follows applies to an individual disturbance at a specific measurement location.

Directional bias, the difference between the most likely USFM measurement (the average) and the venturi or reference measurement, is defined by:

$$
B=\left[\frac{\bar{Q}_{u_{j k}}}{Q_{v_{j k}}}-1\right] \cdot 100
$$

where for a given Re, pipe material, and pipe diameter combination, the average USFM flow rate is given by:

$$
\bar{Q}_{u j k}=\frac{\sum_{i=1}^{n} Q_{u_{i j k}}}{n}
$$

where $i$ is the index for each observation, 1 to 12 (six $10-\mathrm{s}$ measurements $\times 2$ transducer mountings).

From equation 10, the FR for a given combination of Re, pipe material, and pipe diameter is:

$$
F R_{j k}=\frac{\bar{Q}_{u_{j k}}}{Q_{v_{j k}}}
$$


Therefore, to calculate the bias caused by a particular flow-disturbing device at a particular measurement location, the FR data are averaged across all the Re, pipe material, and pipe diameter combinations tested for that particular device, i.e.:

$$
\overline{F R}=\frac{\sum_{k=1}^{p} \sum_{j=1}^{m} F R_{j k}}{m \cdot p}
$$

where

$m=4$ for the four $\operatorname{Re}$

$p=4$ for the number of pipe material and diameter combinations tested for the single elbow disturbance; $p=2$ for all other devices (table 3 ).

In terms of FR, directional bias at each measurement location for a specific flow disturbance is given by:

$$
B=(\overline{F R}-1) \cdot 100
$$

Once $B$ is known, directional bias can be compensated for by using a multiplier (called a "correction factor" in Miller, 1989) given by:

$$
M=\left[1+\frac{B}{100}\right]^{-1}
$$

Precision is a measure of the flow rate measurement repeatability. Again using Miller's (1989) approach, USFM precision at the $95 \%$ confidence level is the product of the standard deviation of the flow rate measurements and the two-tailed Student's value $\left(\mathrm{t}_{\mathrm{st}}\right)$ at the $95 \%$ confidence level. For the number of data points collected in this study, $t_{\mathrm{st}}$ is approximately 1.96. The standard deviation, in percent, for a given flow-disturbing device at a given measurement location is:

$$
\sigma=\sqrt{\frac{\sum_{k}^{p} \sum_{j}^{m} \sum_{i}^{n} Q_{\%}^{2}}{(n \cdot m \cdot p)-1}}
$$

where

$$
Q_{i j k}=\left[\frac{Q_{u_{i j k}}}{\bar{Q}_{u_{j k}}}-1\right] \cdot 100
$$

Precision at the $95 \%$ confidence level is then:

$$
\sigma_{p}=1.96 \cdot \sigma
$$

Device-specific point estimates of accuracy (i.e., the closeness to the actual value) include both directional bias and precision and are given by:

$$
A c c=B \pm \sqrt{\left(1+\frac{1}{n}\right) \cdot \sigma_{p}^{2}}
$$

where $A c c$ is the accuracy in percent.

Continuing to follow Miller's (1989) methodology, accuracy envelopes were developed to characterize USFM performance over the range of downstream measurement locations. The accuracy or performance envelopes incorporated the point (or location-specific) estimates of
USFM directional bias and precision associated with a specific flow-disturbing device. The limits of the performance envelope are expressed in terms of FR on a percentage basis.

\section{Results AND Discussion}

Normalized velocity profiles for flow disturbances SEL, BV5, and BH1 are shown in Figures 4, 5, and 6, respectively. The velocity profiles show the sequential formation of a fully developed velocity profile as the downstream distance increases. At $4.5 \mathrm{D}_{\mathrm{p}}$ downstream from a flow disturbance, most profiles still differed from the fully developed profile. However, by $10 \mathrm{D}_{\mathrm{p}}$, all velocity profiles resembled the fully developed profile. At 22 and $50 \mathrm{D}_{\mathrm{p}}$, the profiles showed the same tendency to approach the fully developed velocity profile in symmetry and shape. Figures 4 and 5 are representative of Group 1 devices (SEL, 2EL, CHK, BH5, and BV5). Figure 6 is representative of those devices that comprise Group 2 (BH1 and BV1).

Figure 7 shows the relationship between the area-weighted RMSE and distance downstream from the Group 1 devices, while figure 8 shows the same relationship for Group 2. The closer the agreement between the measured velocity profile and the calculated theoretical velocity profile, the smaller the RMSE. As expected, the largest deviation from the theoretical, fully developed velocity profile occurred nearest the flow disturbance. Both figures 7 and 8 illustrate that, as the downstream distance increased, the measured velocity profile tended to approach that of the calculated, theoretical velocity profile. The two $50 \%$ open butterfly valve disturbances produced the greatest deviation between the measured and computed theoretical velocity profiles, producing an RMSE of approximately 0.85 at $2 \mathrm{D}_{\mathrm{p}}$ downstream from the flow disturbance. As distance downstream from the flow disturbance increased, the velocity profile became more fully developed and the RMSE approached zero.

As previously stated, the USFM measures the average fluid velocity along the signal path. That measurement is corrected to an area-averaged velocity using a velocity profile correction factor. The internal correction process assumes that the USFM is installed as the manufacturer specifies, and that at the metering cross-section the velocity profile is fully developed. If these conditions are not met, then the internal UFSM velocity correction process will not produce accurate flow measurements. Figures 4, 5, and 6 illustrate that, under the conditions evaluated here, the velocity profile was not fully developed, uniform, or symmetrical near the flow disturbance.

The flow ratio data presented in figure 2 suggest that the USFM under-predicts the actual or reference flow rate near the flow disturbance for the Group 1 devices. For the BV5 flow disturbance, the USFM was $34 \%$ low at $2 \mathrm{D}_{\mathrm{p}}$ and approximately $6 \%$ low at $4.5 \mathrm{D}_{\mathrm{p}}$. However, by $10 \mathrm{D}_{\mathrm{p}}$ the USFM was within $5 \%$ of the actual flow rate, and by $50 \mathrm{D}_{\mathrm{p}}$ the USFM was within about $2 \%$. At downstream distances of $10 \mathrm{D}_{\mathrm{p}}$ and greater, the USFM measurements for all five Group 1 devices were within 5\% of the reference flow rates.

Figures 4 and 5 illustrate that the higher velocities were concentrated near the pipe wall immediately downstream from the flow disturbance for the Group 1 devices. Under 

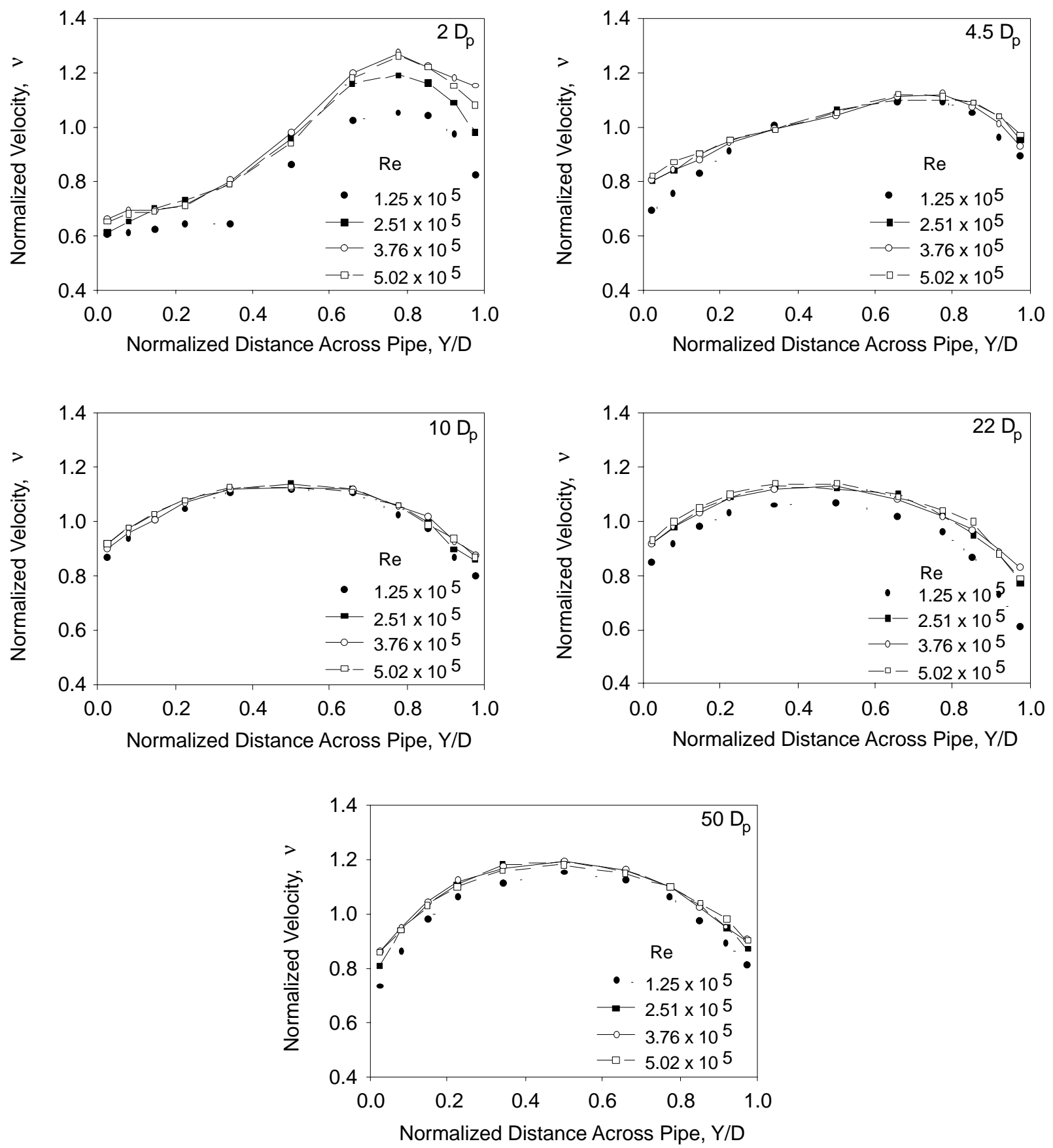

Figure 4. Normalized velocity profiles for single elbow (SEL).

these conditions, the average fluid velocity along the USFM signal path was slower than if the velocity profile were fully developed. Therefore, when the software within USFM applied the velocity correction factor to the disturbed, slower velocity, the displayed flow rate was lower than the actual flow rate. To illustrate this point, we evaluated the distribution of pipe flow as a function of distance from the centerline of the pipe. Starting with the power law equation (eq. 6) and applying continuity, the following relationship was developed:

$$
R=\frac{1}{n}\left\{(2 n+1)\left[1-(1-f)^{1+\frac{1}{n}}\right]-(n+1)\left[1-(1-f)^{2+\frac{1}{n}}\right]\right\}
$$

where

$R=$ fraction of total flow accumulated up to position $f$

$f=$ fraction of inside pipe radius from the centerline.

Equation 19 is plotted in figure 9 along with the measured data for BV5 at 2 and $50 D_{p}\left(\operatorname{Re}=5.02 \times 10^{5}\right)$. Note that from the theoretical curve, $50 \%$ of the flow should occur between the pipe wall and 0.68 of the pipe radius. From the measured data at $2 D_{p}$, only $46 \%$ of the flow was in the area between zero and $f=0.68$. Thus, $54 \%$ of the flow was between $f=0.68$ and $f=1.0$, rather than the expected $50 \%$. Measured data collected at $50 \mathrm{D}_{\mathrm{p}}$ agreed well with the theoretical curve, indicating that the velocity profile was fully developed at $50 \mathrm{D}_{\mathrm{p}}$ downstream from the BV5 flow disturbance. BV5 was 

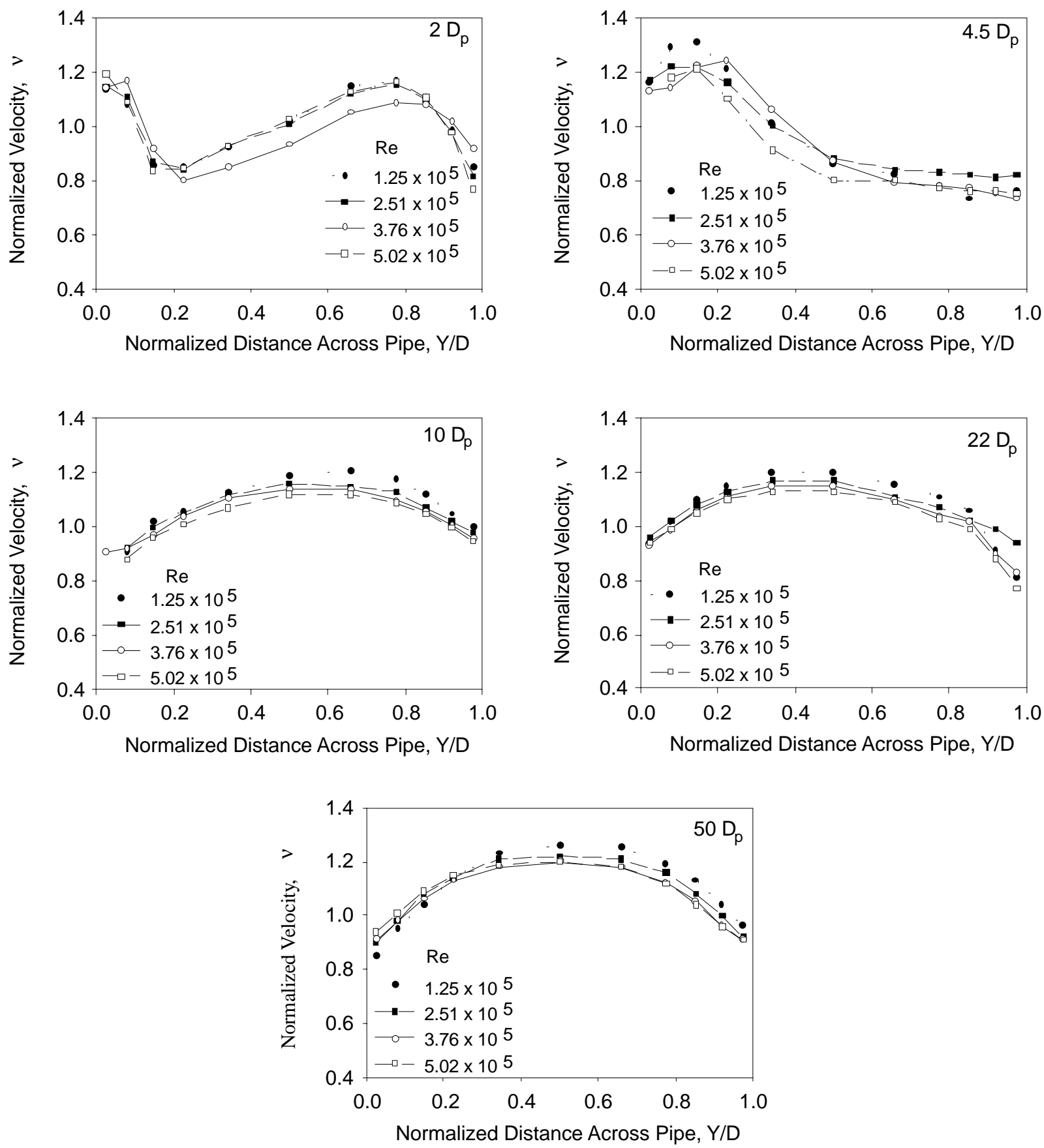

Figure 5. Normalized velocity profiles for $50 \%$ open butterfly valve vertical axis orientation (BV5).

used for this illustration because it produced the largest RMSE of all the tested flow disturbances that fell into Group 1. For the SEL flow disturbance (also Group 1), the trend was similar. At $2 \mathrm{D}_{\mathrm{p}}, 52 \%$ of the flow was concentrated between $0.68<f<1.0$.

The flow ratio data presented in figure 3 present a less clear picture. The BH1 and BV1 flow-disturbing devices behaved similarly in that both caused the USFM to read high near the flow disturbance. The flow ratios for both devices decreased between locations $4.5 \mathrm{D}_{\mathrm{p}}$ and $10 \mathrm{D}_{\mathrm{p}}$, but increased at $10 D_{p}$ and greater. By $10 D_{p}$, the USFM measurements were within 5\% of the reference for both devices. The representative velocity profiles in figure 6 show that the higher velocities were concentrated near the center of the pipe at 2 and $4.5 D_{p}$. The butterfly valve's wafer caused flow separation. Inspection of figure 6 suggests that the fluid reunited after exiting the valve, causing higher velocities to be concentrated near the center of the pipe. However, as the downstream distance increased, the velocity profiles seemed to shift. From 10 to $22 \mathrm{D}_{\mathrm{p}}$, the higher velocities appeared to move from the center of the pipe to nearer the pipe wall. On balance, the USFM read higher than the reference flow rate for the Group 2 devices.

The measured velocity profiles for $\mathrm{BH} 1$ and $\mathrm{Re}=5.02 \times$ $10^{5}$ were used to determine the distribution of flow between $0<f \leq 0.68$ for the 2 and $50 \mathrm{D}_{\mathrm{p}}$ meter locations (fig. 9). The results were $52 \%$ and $50 \%$ for 2 and $50 \mathrm{D}_{\mathrm{p}}$, respectively. These results confirm that the flow was slightly more 

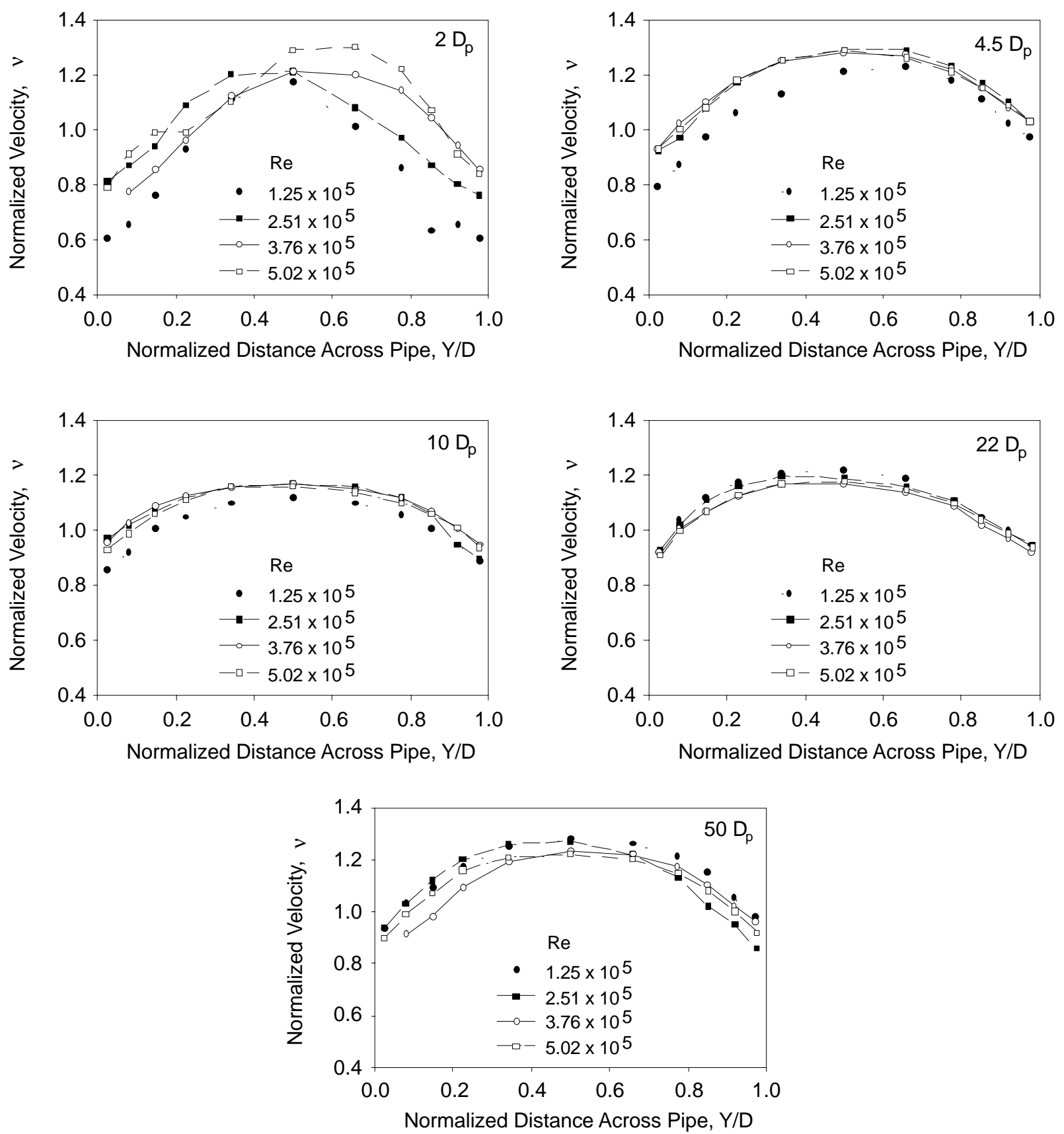

Figure 6. Normalized velocity profiles for $100 \%$ open butterfly valve horizontal axis orientation (BH1).

concentrated near the inside of the pipeline when the metering cross-section was near the $\mathrm{BH} 1$ disturbance.

While examination of the velocity profile and flow ratio data was useful in determining why the USFM responded as it did, the accuracy analysis was instrumental in quantifying USFM performance and developing the USFM flow rate data correction methodology. Accuracy or performance envelopes (Miller, 1989) were developed to characterize USFM performance over the range of flow rates, pipe materials, and pipe diameters evaluated in this study. The accuracy envelopes incorporate the point or location-specific estimates of USFM directional bias and precision associated with a specific flow-disturbing device or class of devices (eq. 18). The points on the accuracy envelope plots represent the directional bias, and the error bars around those points define the precision. The envelopes, presented here in terms of FR on a percentage basis, document USFM performance from 2 to $50 \mathrm{D}_{\mathrm{p}}$ downstream from a given flow disturbance. Accuracy envelopes were developed for the Group 1 devices, and BH1 and BV1, as shown in figures 10 through 12, respectively. The accuracy envelope in figure 10 is based on data for the device that resulted in the largest confidence limit at each $\mathrm{D}_{\mathrm{p}}$. The limits of the envelope are for either BV5 or 2EL, depending on the distance from the flow disturbance. Separate accuracy envelopes were developed for $\mathrm{BH} 1$ and $\mathrm{BV} 1$ because the USFM performance differed between the two devices at downstream distances less than $22 \mathrm{D}_{\mathrm{p}}$.

Figure 10 illustrates that, when using the USFM at $2 D_{p}$ downstream from one of the Group 1 devices, the USFM had 

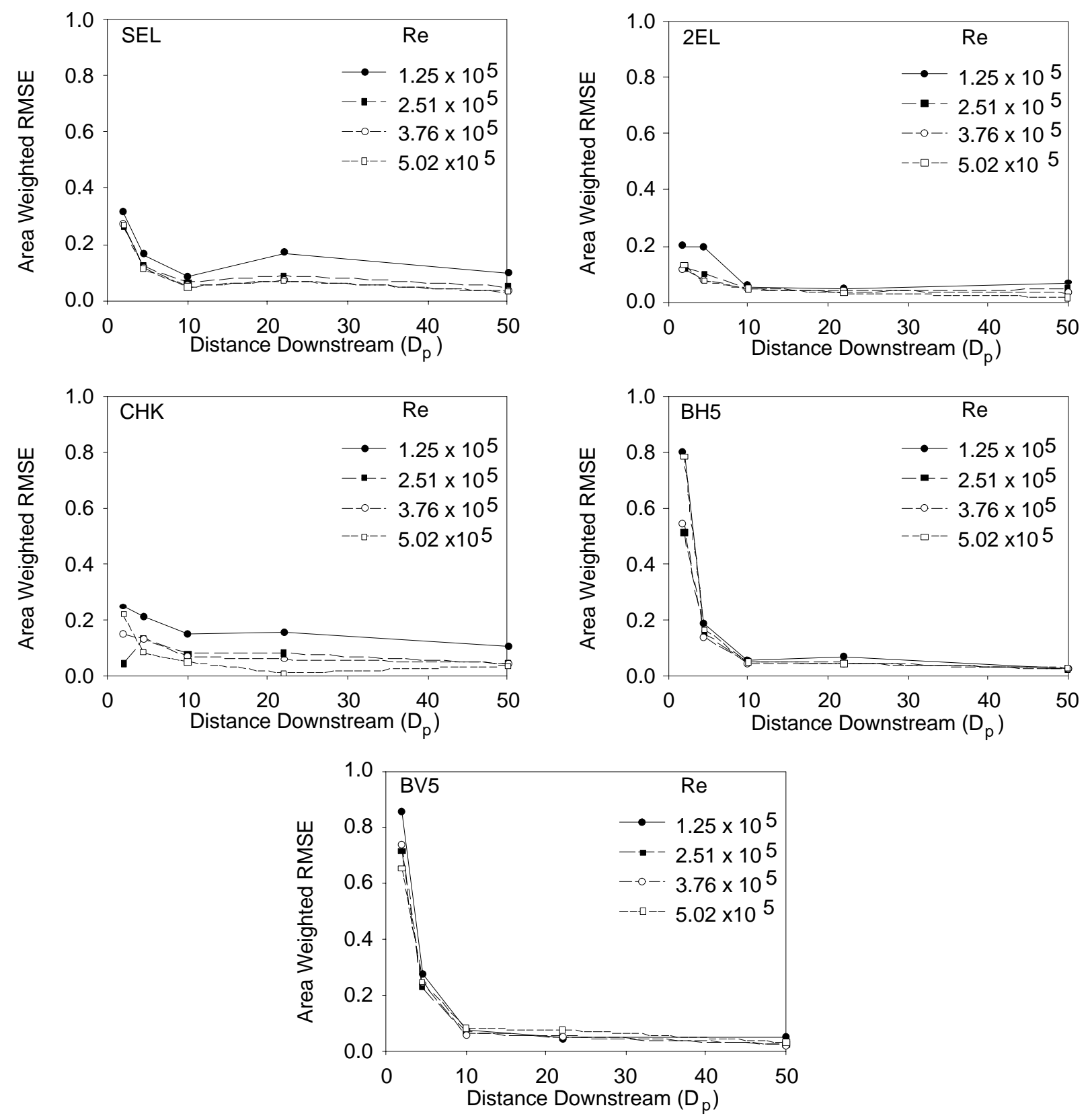

Figure 7. Area-weighted root mean square error (RMSE) vs. downstream distance for Group 1 devices.
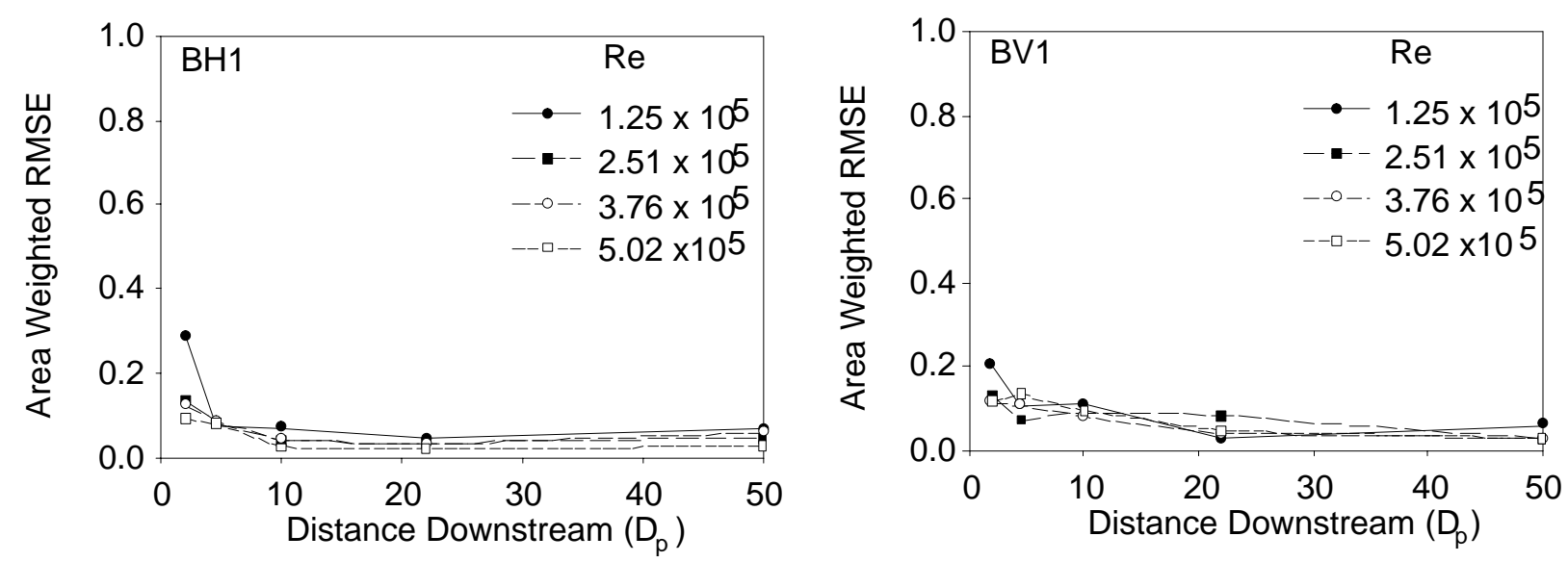

Figure 8. Area-weighted root mean square error (RMSE) vs. downstream distance for Group 2 devices. 


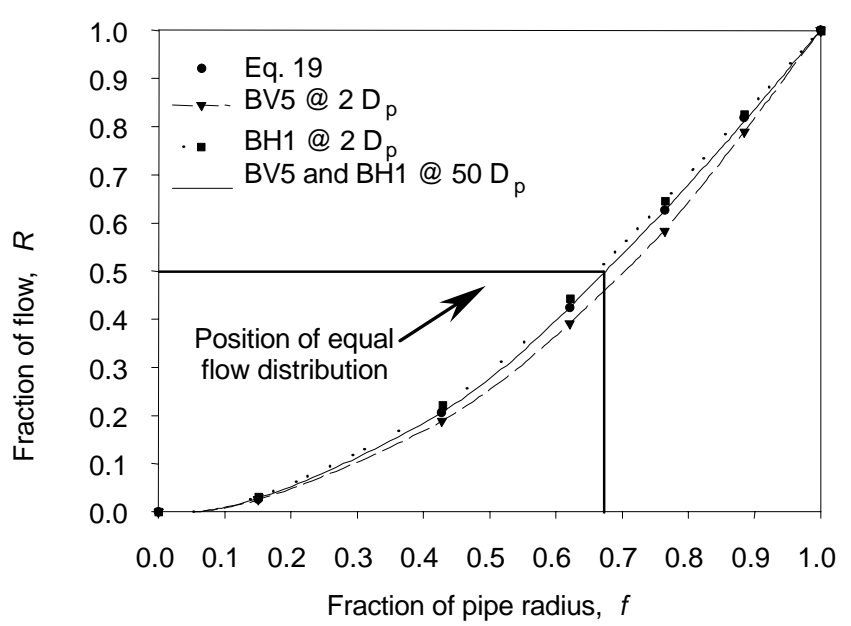

Figure 9. Flow distribution relative to centerline of $15.2 \mathrm{~cm}$ PVC pipe for $50 \%$ open butterfly valve vertical axis orientation (BV5) and $100 \%$ open butterfly valve horizontal axis orientation (BH1).

an average negative directional bias of approximately $15 \%$. This means that at $2 \mathrm{D}_{\mathrm{p}}$ the mean USFM flow rate measurement was approximately $15 \%$ lower than the actual flow rate.

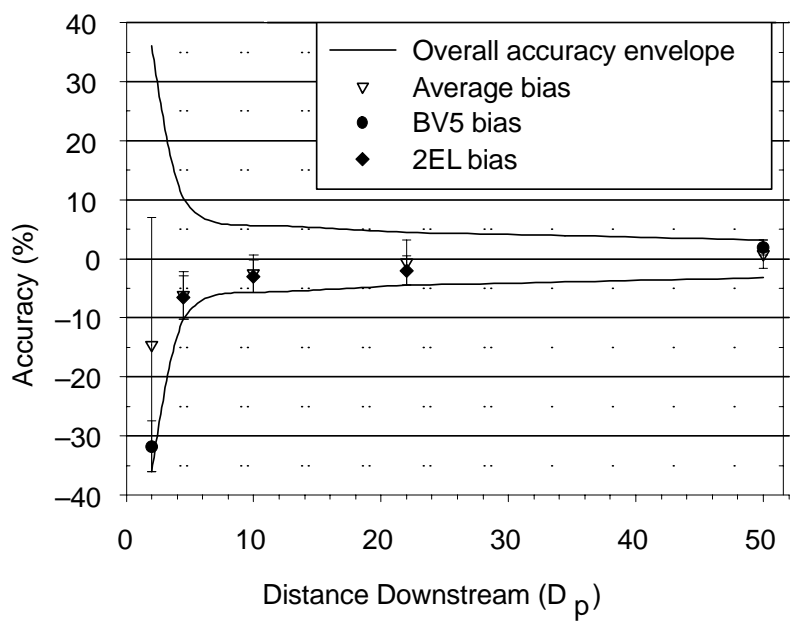

Figure 10. Transit-time ultrasonic flow meter accuracy envelope for Group 1 devices.

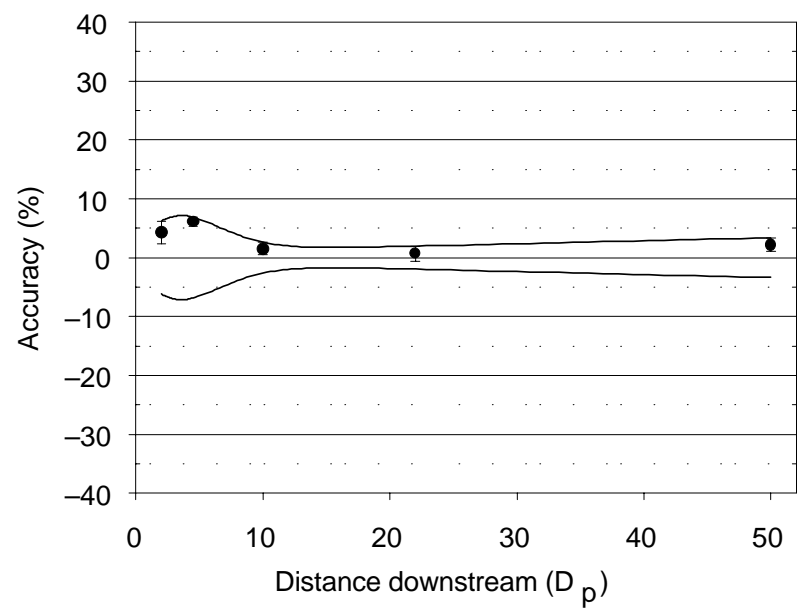

Figure 11. Transit-time ultrasonic flow meter accuracy envelope for $100 \%$ open butterfly valve horizontal axis orientation (BH1).

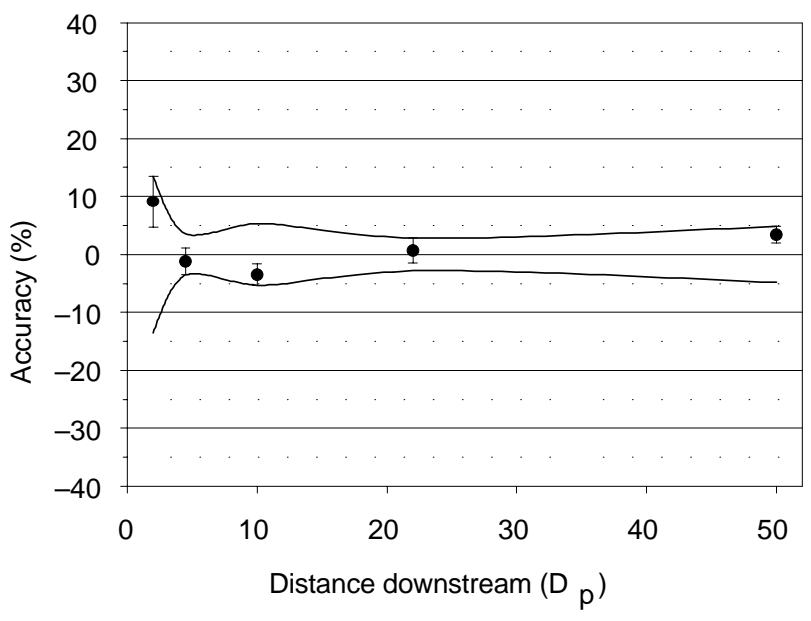

Figure 12. Transit-time ultrasonic flow meter accuracy envelope for $100 \%$ open butterfly valve vertical axis orientation (BV1).

When the imprecision of $\pm 21.5 \%$ is accounted for, the overall accuracy at $2 \mathrm{D}_{\mathrm{p}}$ was $\pm 36.5 \%$, which exceeds the nominal acceptable limit of $\pm 5 \%$. As expected, at $50 \mathrm{D}_{\mathrm{p}}$ the USFM exhibited essentially no directional bias, and the overall accuracy had improved to less than $\pm 3.5 \%$.

Equation 14 was used to calculate a directional bias multiplier for each downstream measurement location for the Group 1 devices. A second-order polynomial was fit to the calculated multiplier (fig. 13). The regression relationship can be used to predict a directional-bias multiplier for any downstream measurement location between 2 and $50 \mathrm{D}_{\mathrm{p}}$. Directional bias can be removed from the raw USFM measurement simply by multiplying the USFM flow rate measurement by the multiplier. The accuracy after correction of the USFM measurement is shown in figure 14. The estimated accuracy of any corresponding corrected flow rate measurement can be found by using the regression equation presented in figure 14. Figure 14 illustrates that the accuracy of the corrected USFM is within $\pm 4 \%$ of actual flow for all measurements taken at $4.5 \mathrm{D}_{\mathrm{p}}$ and beyond. Without correction, the accuracy at $4.5 \mathrm{D}_{\mathrm{p}}$ is $\pm 10 \%$ (fig. 10). Obviously, the multiplier and associated accuracy estimates presented in figures 13 and 14 are only applicable to the specific piping conditions and flow-disturbing devices that

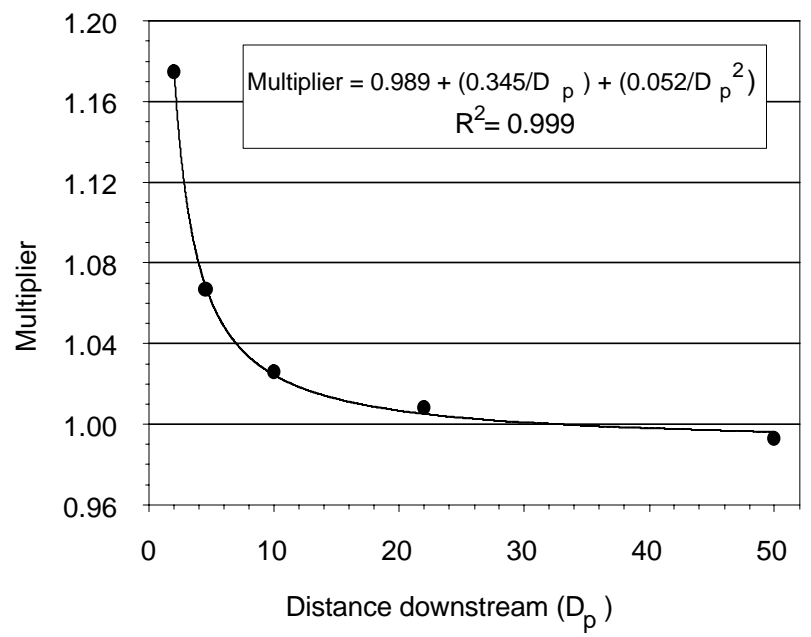

Figure 13. Multiplier used to remove transit-time ultrasonic flow meter directional bias, Group 1 flow-disturbing devices. 


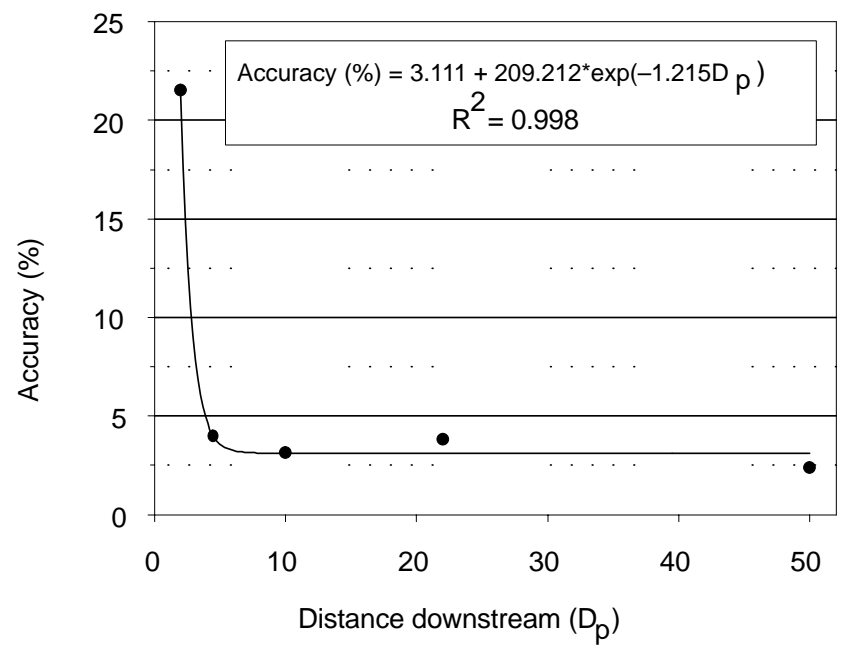

Figure 14. Transit-time ultrasonic flow meter accuracy after directional bias removed, Group 1 flow-disturbing devices.

were evaluated in this study and placed into the Group 1 category.

The accuracy envelope for BH1 (fig. 11) shows that the directional bias was positive for all downstream distances and the maximum directional bias was approximately $7 \%$. Figure 12 shows that for the BV1 device, the directional bias at 4.5 and $10 \mathrm{D}_{\mathrm{p}}$ was negative, while at 2, 22, and $50 \mathrm{D}_{\mathrm{p}}$ it was positive. Figures 11 and 12 indicate that, when measuring downstream from fully open wafer-type butterfly valves, the preferred orientation of the USFM transducers is parallel with the pivot axis of the valve, all else being equal. This orientation produced the most accurate results over the range of downstream distances evaluated here. Measuring across a vertical plane is not recommended because of potential air entrainment near the top of the pipe.

\section{SummarY AND CONCLUSION}

The performance of a transit-time ultrasonic flow meter was evaluated downstream from non-ideal, flow-disturbing piping configurations typically encountered in irrigation systems. Non-ideal piping configurations were created using three flow-disturbing devices: a $90^{\circ}$ elbow, a disk-type check valve, and a wafer-type butterfly valve. These devices were arranged to produce seven different flow-disturbing configurations. Three pipe materials were used: polyvinyl chloride (PVC), Class 20 steel, and aluminum. USFM performance was tested across a range of flow rates corresponding to $\operatorname{Re}$ of $1.25 \times 10^{5}, 2.51 \times 10^{5}, 3.76 \times 10^{5}$, and $5.02 \times 10^{5}$. Measurements taken at 2, 4.5, 10, 22, and 50 pipe diameters downstream of the flow disturbance were compared to laboratory standard meters.

The USFM performance and corresponding flowdisturbing devices fell into one of two groups. Downstream from the devices that fell into Group 1 (single elbow, two elbows, check valve, or $50 \%$ open butterfly valve with either vertical or horizontal orientation), the USFM consistently under-predicted the actual flow near the flow disturbance but became more accurate as the downstream distance increased. The regression analysis performed on Group 1 devices showed that the USFM performance was not significantly different for the three pipe materials, two pipe diameters, and four flow rates. Downstream from the devices that fell into Group 2 (100\% open butterfly valve with either vertical or horizontal orientation), the USFM both over- and under-predicted the actual flow rates near the flow disturbance; but as the downstream distance increased, the USFM consistently over-predicted the actual flow rate.

Without any correction, the USFM inaccuracy at $2 \mathrm{D}_{\mathrm{p}}$ was as high as $\pm 36.5 \%$ of the actual flow rate. At $4.5 D_{p}$ the inaccuracy was approximately $\pm 10 \%$. At 10,22 , and $50 \mathrm{D}_{\mathrm{p}}$ the inaccuracy was within approximately $\pm 5 \%$ for all the tested devices. Based on these results, we recommend that the USFM be installed with at least $10 \mathrm{D}_{\mathrm{p}}$ of straight, unobstructed pipe upstream from the measurement location. If this installation requirement cannot be met, a multiplier was developed to correct for directional bias in the USFM measurement downstream from Group 1 devices. Applying the multiplier at $4.5 \mathrm{D}_{\mathrm{p}}$ and higher resulted in accuracies within $\pm 4 \%$ of the actual flow rate.

\section{REFERENCES}

ASME. 1971. Fluid Meters: Their Theory and Application. 6th ed. H. S. Bean, ed. New York, N.Y.: American Society of Mechanical Engineers.

. 1985. Measurement of Liquid Flow in Closed Conduits Using Transit-Time Ultrasonic Flowmeters. ASME MFC-5M-1985. New York, N.Y.: American Society of Mechanical Engineers.

Cocking, S. 1997. Personal Communication. Houston, Texas: Peek Measurement. 1994. Ultrasonic Flow Meters for Liquid Measurement. Houston, Texas: Peek Measurement.

Daily, J. W., and D. R Harleman. 1966. Fluid Dynamics. Reading, Mass.: Addison-Wesley.

Hanson, B. R., and L. J. Schwankl. 1998. Error analysis of flowmeter measurements. J. Irrigation and Drainage Eng., ASCE 124(5): 248-256.

ISO. 1991. Measurement of Fluid Flow by Means of Pressure Differential Devices - Part I. 5167-1. New York, N.Y.: International Organization for Standardization.

Luckey, R., F. Heimes, and N. Gaggiani. 1980. Calibration and testing of selected portable flow meters for use on large irrigation systems. Water Resources Investigations 80-72. Washington, D.C.: U.S. Geological Survey.

Miller, R. W. 1989. Flow Measurement Engineering Handbook. New York, N.Y.: McGraw-Hill.

Noffke, M. 1988. Achieving accurate irrigation water measurement with propeller meters. In Planning Now for Irrigation and Drainage in the 21st Century, 659-664. D. R. Hay, ed. New York, N.Y.: American Society of Civil Engineers.

Omega Engineering. 1992. Complete Flow and Level Measurement Handbook and Encyclopedia. Vol. 28. Stamford, Conn.: Omega Engineering, Inc.

Peek Industries. 1996. Model ISTT-P Portable Transit-Time Ultrasonic Flowmeter, Product Manual. Houston, Texas: Peek Industries.

Replogle, J. A., and G. S. Birth. 1991. Flow. Chapter 5 in Instrumentation and Measurement for Environmental Sciences. 3rd ed. Z. A. Henry, G. C. Zoerb, and G. S. Birth, eds. St. Joseph, Mich.: ASAE.

Replogle, J. A., A. J. Clemmens, and M. G. Bos. 1990. Measuring irrigation water. In Management of Farm Irrigation Systems, 315-370. G. J. Hoffman, T. A. Howell, and K. H. Solomon, eds. St. Joseph, Mich.: ASAE.

Riezenman, M. J. 1989. Ultrasonic meters go with the flow. Mech. Eng. 111(9): 74-77. 
SAS. 1987. SAS System for Elementary Statistical Analysis. Cary, N.C.: SAS Institute, Inc.

Schroeder, M. 1985. Revised Irrigation Pumping Plant Test Procedure Manual. Lincoln, Nebr.: University of Nebraska-Lincoln.
Upp, E. L. 1993. Fluid Flow Measurement: A Practical Guide to Accurate Flow Measurement. Houston, Texas: Gulf Publishing Company, Daniel Industries.

U.S. DOI. 1997. Water Measurement Manual. 3rd ed. Washington, D.C.: U.S. Department of the Interior, Bureau of Reclamation. 